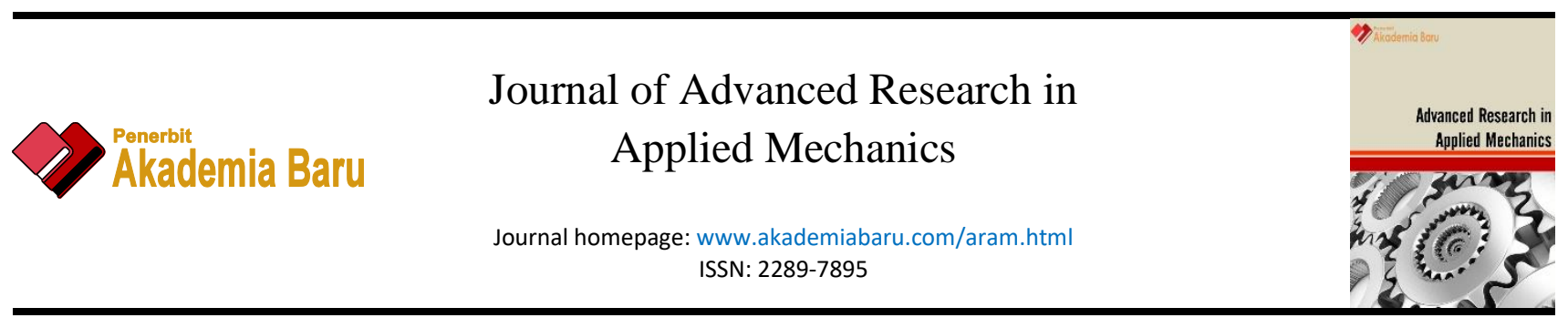

\title{
Measurement of Fluid Flow and Heat Transfer Performance in Rectangular Microchannel using Pure Water and $\mathrm{Fe}_{3} \mathrm{O}_{4}-\mathrm{H}_{2} \mathrm{O}$ Nanofluid
}

\author{
Saidu Bello Abubakar ${ }^{1}$, Nor Azwadi Che Sidik ${ }^{2,}{ }^{*}$, Siti Nurul Akmal Yusof ${ }^{2}$ \\ 1 Department of Mechanical Engineering, Kano University of Science and Technology, Wudil p.m.b 3244 Kano, Nigeria \\ 2 Malaysia - Japan International Institute of Technology (MJIIT), University Teknologi Malaysia,Jalan Sultan Yahya Petra,54100 Kuala Lumpur, \\ Malaysia
}

\section{ABSTRACT}

\begin{abstract}
In this study, the three-dimensional rectangular silicon microchannel heat sink (MCHS) were analyzed numerically to investigate the fluid flow and heat transfer performance using pure water and $\mathrm{Fe}_{3} \mathrm{O}_{4}-\mathrm{H}_{2} \mathrm{O}$ as working fluids. The numerical method is based on finite volume method. CFD software's involving GAMBIT and FLUENT were employed to perform the investigation numerically in the range of Reynolds number 140, 700 and 1400 and for volume fractions are in the range of $\varphi=0.4, \varphi=0.6$ and $\varphi=0.8$. It is observed that the presence of $\mathrm{Fe}_{3} \mathrm{O}_{4}-\mathrm{H}_{2} \mathrm{O}$ has effect of reducing the tempreture as particle volume fraction of Fe3O4- $\mathrm{H} 2 \mathrm{O}$ increases due to its higher dynamic viscosity and lower heat capacity compared to pure water. The results show that the highest heat transfer enhancement is anticipated for $\mathrm{Fe}_{3} \mathrm{O}_{4}-\mathrm{H}_{2} \mathrm{O}$ with volume fraction of $0.8 \%$ due to higher thermal conductivity and Nusselt number. The Nusselt number $\mathrm{Fe}_{3} \mathrm{O}_{4}-\mathrm{H}_{2} \mathrm{O}$ increased with the increase of volume fraction and with the increase of Reynolds number. Overall, the simulated results showed that the heat transfer performance of $\mathrm{Fe}_{3} \mathrm{O}_{4}-\mathrm{H}_{2} \mathrm{O}$ with $0.8 \%$ was better than that of $\mathrm{Fe}_{3} \mathrm{O}_{4}-\mathrm{H} 2 \mathrm{O}$ with $0.4 \%$, of $\mathrm{Fe}_{3} \mathrm{O}_{4}-\mathrm{H} 2 \mathrm{O}$ with $0.6 \%$, and pure water. Increasing the thermal conductivity of working fluid enhanced the heat transfer performance of MCHS.
\end{abstract}

Keywords:

Laminar flow; Rectangular microchannel; nanofluids

Copyright $@ 2020$ PENERBIT AKADEMIA BARU - All rights reserved

\section{Introduction}

The severe need by user for greater IC speeds, functionality and minimization has fueled an extraordinary acceleration in chip power dissipation. Amongst all the problems facing by the chip and computer designers is none other than more burning than the soaring levels of power flowing through the integrated circuits. Thermal demands are continuously on the rise. Increasing process speeds (up to $2.5 \mathrm{GHz}$ ), decreasing product sizes and styling requirements cause higher and higher heat loads on the products and consequently thermal management is becoming a critical bottleneck to system performance. The National Electronic Technology Roadmap, 1997 has acknowledge the expectation that the Moore' law improvements in the semiconductor technology will continue into

\footnotetext{
* Corresponding author.

E-mail address: azwadi@utm.my (Nor Azwadi Che Sidik)
}

https://doi.org/10.37934/aram.68.1.921 
the second decade of the 21st century [1]. Due to these enhancements, the chip level heat fluxes have gone up tremendously [2].

The concept of the microchannel heat sinks was first introduced in 1981 by Tuckerman and Peas [3]. They demonstrated that the microchannel heat sinks, consisting of micro rectangular flow passages, have a higher heat transfer coefficient in laminar flow regime than in turbulent flow through macro size channels. Therefore, a significantly high heat flux can be dissipated by using such a microchannel heat sink. There are two main configurations for the application of microchannel cooling which are direct cooling and indirect cooling as shown in Figure 1. Direct cooling requires a direct contact between the surface to be cooled and the coolant fluid as illustrated in Figure 1(a). This scheme reduces the thermal resistance between the surface and the coolant and thus, enhances the cooling effectiveness. However, electrical and chemical compatibility between the coolant and device itself needs to be ensured for this system to work [4]. An alternative to the above configuration is the use of a metallic heat sink to conduct the heat away from the device to a coolant which is forced through circular or noncircular grooves in the heat sink. Such an indirect cooling configuration shown in Figure 1(b) allows for a greater flexibility in coolant selection at the cost of increased thermal resistance between the device and the heat sink due to the heat diffusion resistance in the heat sink itself [5]

Microchannels are very fine channels of the width of a normal human hair and are widely used for electronic cooling purposes. In a MCHS, multiple microchannels are stacked together as shown in Figure 1(b) which can increase the total contact surface area for heat transfer enhancement and reduce the total pressure drop by dividing the flow among many channels. Liquid or gas is used as a coolant to flow through these microchannels.

The large surface area of MCHS enables the coolant to take away large amounts of energy per unit time per unit area while maintaining a considerably low device temperature. Using these MCHS, heat fluxes can be dissipated at relatively low surface temperatures [6].

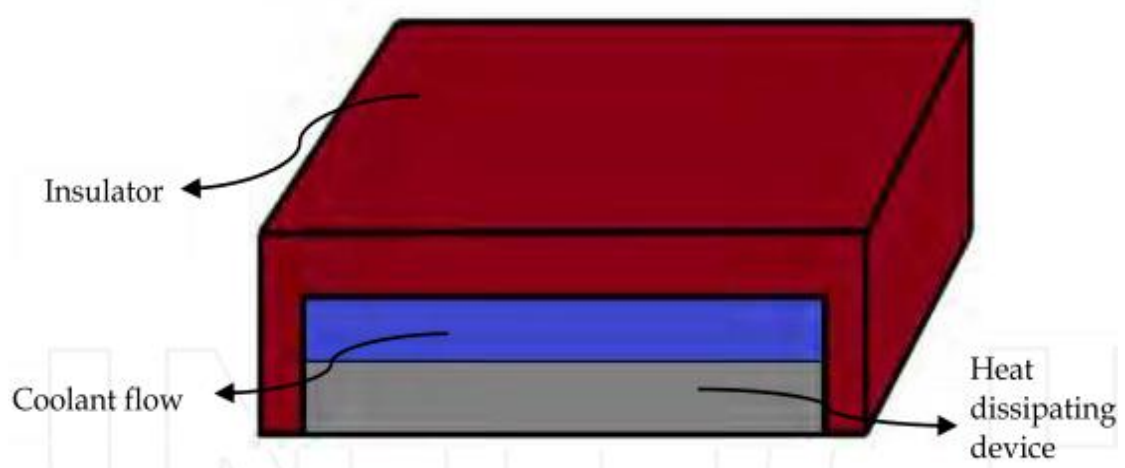

(a)

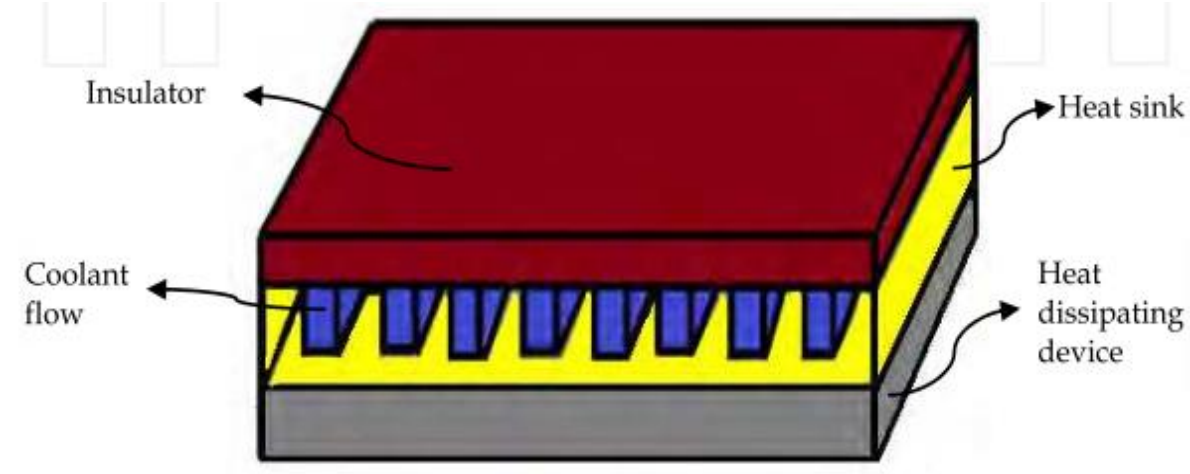

(b)

Fig. 1. Schematic diagram of the (a) direct cooling and (b) indirect cooling [6] 
Peng and Peterson [7] experimentally investigated the flow characteristics of water flowing through rectangular microchannels with hydraulic diameters ranging from 133 to $367 \mu \mathrm{m}$ and width to height ratios from 0.333 to 1 . From their results, the friction factor and the Reynolds number do not seem to be inversely proportional, as indicated by the conventional theory for laminar flow. In 2002, Qu and Mudawar [8] also studied the same channel geometry. Their results show that the heat flux and Nusselt number have much higher values near the channel inlet and vary around the channel edge, approaching zero in the corners. Result also showed that increasing the thermal conductivity of the solid substrate reduces the temperature at the heated base surface of the heat sink, especially near the channel outlet. In most cases, water is used as a coolant. But water is well known as heat transfer fluids which have low thermal conductivity that greatly limits the heat exchange efficiency. Other base fluids like engine oil and ethylene glycol also have low thermal conductivity.

In order to enhance the thermal conductivity of the conventional fluid and heat transfer characteristics, the solid particles are suspended into the base fluid used in the heat exchangers. Adding particles into the base fluid enhances the thermal conductivity, because the thermal conductivity of the solid metal particles is higher than the base fluid. Nanofluids contain a small fraction of solid nanoparticles in base fluids. Nanofluids have offered challenges to thermal engineers and attracted many researchers over the past decade to determine the reasons for anomalous enhancement of thermal conductivity and heat transfer in their applications [9-14]. According to Wang et al., [15], the thermal conductivity of nanofluids depends on parameters including the thermal conductivities of the base fluid and the nanoparticles, the volume fraction, the surface area, and the shape of the nanoparticles, and the temperature. Until now, there is no reliable formula to predict thermal conductivity of nanofluids satisfactorily.

In another work done by Das et al., [16] examined the effect of temperature on thermal conductivity enhancement for nanofluids containing $\mathrm{Al}_{2} \mathrm{O}_{3}(38.4 \mathrm{~nm})$ or $\mathrm{CuO}(28.6 \mathrm{~nm})$ through an experimental investigation using temperature oscillation method. They reported that smaller particles show greater enhancements of thermal conductivity with temperature than larger particles.

Measurement of the effective thermal conductivity of nanofluids by a steady state parallel-plate technique was done by Wang et al., [17]. The base fluids (water ethylene glycol (EG), vacuum pump oil and engine oil) contained suspended $\mathrm{Al}_{2} \mathrm{O}_{3}$ ) and $\mathrm{CuO}$ nanoparticles of 28 and $23 \mathrm{~nm}$ of average diameters, respectively. They reported the thermal conductivity of all nanofluids were higher than those of their base fluids.

Recently, various methodologies have been done to study the MCHS performance using nanofluid [18-23]. Chein and Chuang [18] conducted studies on MCHS performance using nanofluids. $\mathrm{CuO}-\mathrm{H} 2 \mathrm{O}$ nanofluid has been used as a coolant to experimentally study the heat performance of silicon trapezoidal shaped MCHS. They found that nanofluid-cooled MCHS could absorb more energy than pure water-cooled MCHS when the flow rate was low. However, for high flow rates, the heat transfer was dominated by the volume flow rate and nanoparticles did not contribute to the extra heat absorption.

Lee and Mudawar [19] studied experimentally the micro-channel cooling benefits of water-based nanofluids containing small concentrations of $\mathrm{Al} 2 \mathrm{O} 3$ for single-phase and two-phase heat transfer. It has been found that high thermal conductivity of nanoparticles is shown to enhance the single-phase heat transfer coefficient, especially for laminar flow. Higher heat transfer coefficients were achieved mostly in the entrance region of microchannels. Unfortunately, they found that nanoparticles are not suitable to be used in two-phase because nanoparticles caused catastrophic failure by depositing into large clusters near the channel exit.

In another research done by Mohammed et al., [20] studied the impact of using various types of nanofluids on heat transfer and fluid flow characteristics in triangular shaped microchannel heat sink 
(MCHS). An aluminium MCHS performance is examined using water as a base fluid with different types of nanofluids such as $\mathrm{Al}_{2} \mathrm{O}_{3}, \mathrm{Ag}, \mathrm{CuO}$, diamond, $\mathrm{SiO} 2$, and $\mathrm{TiO} 2$ as the coolants with nanoparticle volume fraction of $2 \%$. The result shows that diamond- $\mathrm{H} 2 \mathrm{O}$ are recommended to achieve overall heat transfer enhancement whereas $\mathrm{Ag}-\mathrm{H} 2 \mathrm{O}$ nanofluids water is recommended to achieve low pressure drop and low wall shear stress.

Noh et al., [24] investigated the effect of various type of coolants using water and different types of nanofluids on the cooling performance of the microchannel heat sink (MCHS). They reported that the use of Diamond-H2O as the coolant leads to higher efficiency of heat transfer by $0.3 \%$ compared to other nanofluid agents and base fluid. It is also shown that the trend of Nusselt number obeys the increment of Reynolds number.

The used of nanofluids as a coolant for microchannel heat sink on semiconductor and electrical field is found out more effective and researches on this application are increase from time to time. Most of the researches focused on the material properties of microchannel heat sink can enhance the heat transfer. There are a few journals and papers discuss about heat transfer mechanism and research on material properties of the microchannel using $\mathrm{Fe}_{3} \mathrm{O}_{4}-\mathrm{H}_{2} \mathrm{O}$. However, the aim of this study is to focus on the heat transfer enhancement using $\mathrm{Fe}_{3} \mathrm{O}_{4}-\mathrm{H}_{2} \mathrm{O}$ in $\mathrm{MCHS}$. The numerical analysis is based on FLUENT finite volume method. The micro-heat sink model consists of a $10 \mathrm{~mm}(\mathrm{~L}) \times 57 \mu \mathrm{m}$ (W) $\times 180 \mu \mathrm{m}$ (D) were used. Water and $\mathrm{Fe}_{3} \mathrm{O}_{4}-\mathrm{H}_{2} \mathrm{O}$ were used as a working fluid.

\section{Methodology}

\subsection{Description of the Problem and Conservation Equations}

The schematic diagram of the MCHS is shown in Figure 2. The electronic component is idealized as a constant heat flux boundary condition at the heat sink top wall. Here we consider a rectangular channel of dimension $(900 \mu \mathrm{m} \times 100 \mu \mathrm{m} \times 10 \mathrm{~mm})$ applied constant heat flux of $900000 \mathrm{~W} / \mathrm{m}^{2}$ heat sink top wall. Variable working fluids (Pure water and $\mathrm{Fe}_{3} \mathrm{O}_{4}-\mathrm{H}_{2} \mathrm{O}$ ) flowing at temperature 293k on account of uniform inlet velocity which depends on the Reynolds number. Heat transport in the unit cell is a conjugate problem which combines heat conduction in the solid and convective heat transfer to the coolant (Pure water and $\mathrm{Fe}_{3} \mathrm{O}_{4}-\mathrm{H}_{2} \mathrm{O}$ ).

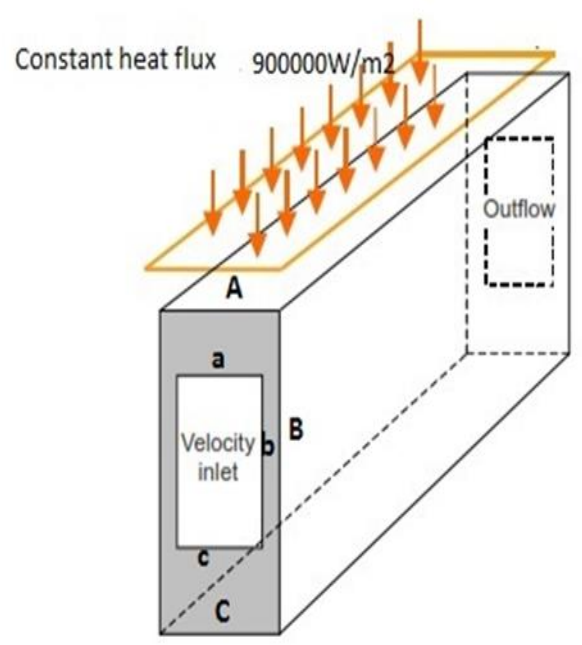

Fig. 2. Schematic of unit cell rectangular microchannel heatsinks 
In order to determine the distribution of pressure, velocity and temperature to predict convective heat transfer rate, the principles of conservation of mass, conservation of momentum and conservation of energy are applied. These conservation principles lead to the so-called continuity, Navier-Stokes and energy equations. The continuity, momentum and energy equations for the problem can be written as

$\frac{\partial u}{\partial x}+\frac{\partial v}{\partial y}+\frac{\partial w}{\partial z}=0$

$\rho\left(u \frac{\partial u}{\partial x}+v \frac{\partial v}{\partial y}+w \frac{\partial w}{\partial z}\right)=-\frac{\partial p}{d x}+\mu\left(\frac{\partial^{2} u}{\partial x^{2}}+\frac{\partial^{2} u}{\partial y^{2}}+\frac{\partial^{2} u}{\partial z^{2}}\right)$

$\rho\left(u \frac{\partial v}{\partial x}+v \frac{\partial v}{\partial y}+w \frac{\partial v}{\partial z}\right)=-\frac{\partial p}{d y}+\mu\left(\frac{\partial^{2} v}{\partial x^{2}}+\frac{\partial^{2} v}{\partial y^{2}}+\frac{\partial^{2} v}{\partial z^{2}}\right)$

$\rho\left(u \frac{\partial w}{\partial x}+v \frac{\partial w}{\partial y}+w \frac{\partial w}{\partial z}\right)=-\frac{\partial p}{d z}+\mu\left(\frac{\partial^{2} w}{\partial x^{2}}+\frac{\partial^{2} w}{\partial y^{2}}+\frac{\partial^{2} w}{\partial z^{2}}\right)$

$\rho C_{p}\left(u \frac{\partial T}{\partial x}+v \frac{\partial T}{\partial y}+w \frac{\partial T}{\partial z}\right)=k\left(\frac{\partial^{2} T}{\partial x^{2}}+\frac{\partial^{2} T}{\partial y^{2}}+\frac{\partial^{2} T}{\partial z^{2}}\right)$

\subsection{Boundary Condition}

To achieve solutions to the flow and temperature fields, boundary conditions must be employed and specified. Boundary conditions are mathematical formulation describing what takes place physically at aboundary. However, for the purpose of this study it is necessary to specify boundary conditions. The following are the boundary equations under study.

\subsubsection{Hydraulic boundary conditions}

For hydraulic boundary condition, the velocity is zero at all boundaries except the channel inlet and outlet. A uniform velocity is applied at the channel inlet. The velocity is obtained from the Reynolds number.

$u=\frac{R_{e} * \mu_{f}}{\rho * d_{h}}$

where $d_{h}=$ hydraulic diameter. The flow is fully developed at channel outlet

$\frac{\partial u}{\partial x}=0, \frac{\partial v}{\partial x}=0, \frac{\partial w}{\partial x}=0$

\subsubsection{Thermal boundary conditions}

For thermal boundary conditions, adiabatic boundary conditions are applied to all the boundaries of the solid except the heat sink top wall, where a constant heat flux is assumed

$q^{\prime \prime}=-k_{s} \frac{\partial T}{\partial z}$

At the channel inlet, the liquid temperature is equal to a given constant inlet temperature.

$T=T_{\text {in }}=293 k$ 
The flow is also assumed thermally fully developed at the channel outlet because the change of temperature gradient along the flow direction at the channel exit is usually very small even for very large Reynolds numbers. Thus, large numerical error will not be introduced by the exit thermal boundary condition.

$\frac{\partial^{2} T}{\partial x^{2}}$

\subsection{Important Parameter}

In this are analysis, there are important parameters to be employed. The parameters are:

Hydraulic diameter:

$D_{h}=\frac{4(h * w)}{2(h+w)}$

Nusselt number:

$N_{u}=\frac{h D_{h}}{k}$

Reynold number:

$R_{e}=\frac{\rho u D_{h}}{\mu}$

\subsection{Geometry Modelling}

A microchannels heat sink usually consists of a number of identical channels. Numerical simulation for entire unit require large amount of CPU time. By taking advantage of symmetry of the channels, a unit cell consisting of only one channel and the surrounding solid is considered for the numerical investigation. Figure 3 shows the schematic of a unit cell rectangular MCHS.

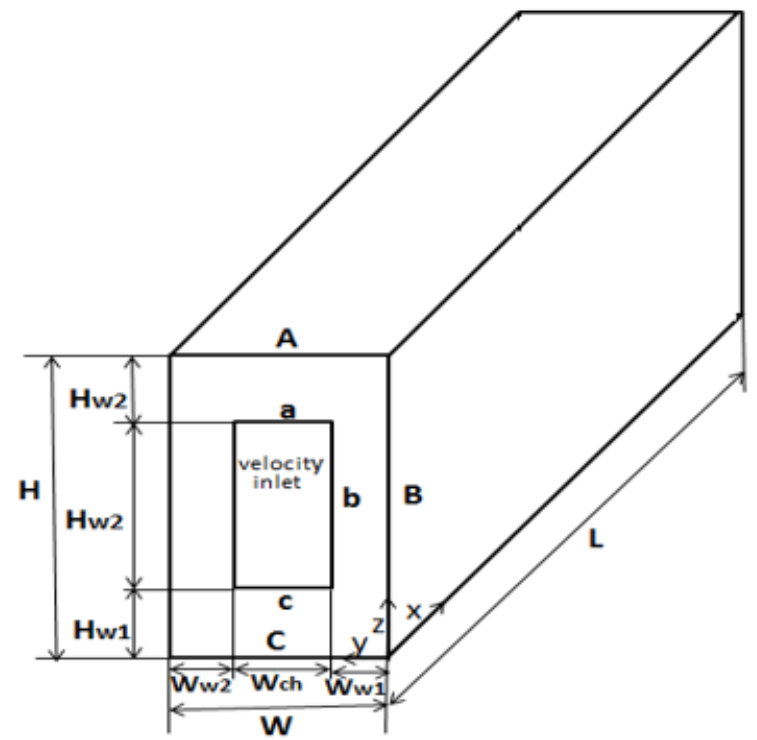
A: Heat sink top wall
B: Heat sink side wall
C: Heat sink bottom wall
a: Channel top wall
b: Channel side wall
c: Channel base wall

Fig. 3. Schematic of a unit cell rectangular MCHS 


\subsection{Numerical Solution}

The numerical methodology is based on finite volume method. Computer fluid dynamic (CFD) code which is FLUENT solver was used. The computational mesh was generated by using Gambit software. For this case, the double-precision solver will be selected since it more accurate. For conjugate problems involving high thermal-conductivity ratios or high aspect- ratio grids, convergence and accuracy may be impaired with the single precision solver, due to insufficient transfer of boundary information. Fluid properties are updated for every working fluid, based on current solution. The velocity inlet is dependents on the Reynolds number. The value which is $10^{-6}$ was used for the convergence criterion of Fluent iteration process for continuity and momentum equation. For energy the convergence criterion is set to $10^{-8}$.

\section{Results}

\subsection{Grid Independent Test}

The present work consists of a rectangular straight microchannel with constant heat flux at the top wall heatsink. Before the complete simulation was carried out the computational domain was tested for better result accuracy and time effectiveness. In this case, three different mesh size models were modelled using GAMBIT software. The model with fines mesh size is taken as reference for other models. Table 1 shows the mesh type, number of element and maximum deviation from channel outlet temperature for the three-mesh size. From the grid independence test result, model with medium mesh size was selected for simulation model since the maximum deviation of the channel outlet temperature is approximately $0.015 \%$ which is very small and not significant to the result of the numerical analysis.

Table 1

Grid independent test

\begin{tabular}{llll}
\hline Mesh type & Course & Medium & Fine \\
\hline Number of elements & 28000 & 127500 & 780000 \\
$\begin{array}{l}\text { Maximum deviation from channel outlet } \\
\text { temperature }\end{array}$ & $0.03 \%$ & $0.016 \%$ & References \\
\hline
\end{tabular}

\subsubsection{Data Validation}

To ensure the validity of this simulation analysis of three dimensional rectangular straight microchannel, data validation was done for the accuracy of the result. The data is validated against Shah and London with the Average Nusselt number evaluated and plotted in Figure 4 as a function of longitudinal distance $x$. The validation correlation of average Nusselt number is given by

$\bar{N}_{u}=\frac{q^{\prime \prime} d_{h}}{k_{f}\left(T_{\Gamma, m}-T_{m}\right)}$

$T_{\Gamma, m}$ is the average temperature at the boundary

$T_{m}$ bulk temaperature 


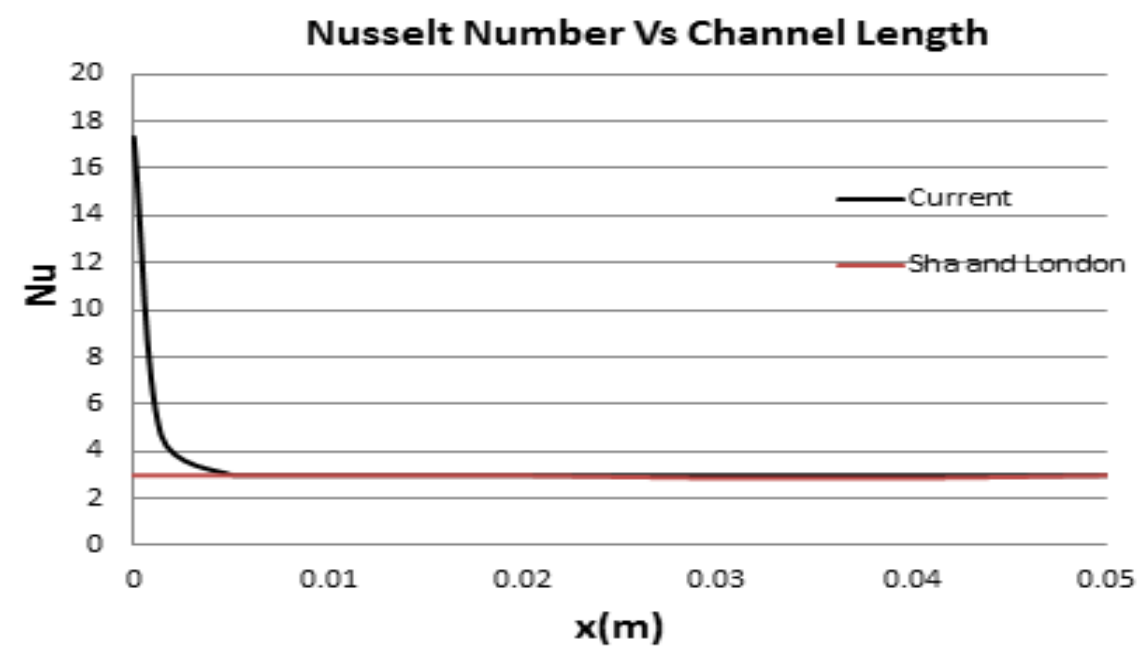

Fig. 4. Validation of average Nusselt number along micro channel length

The average Nusselt number is validated plotted in Figure 4, classical convective heat transfer and solution for fully developed flow was provided bay Shah and London. The average Nusselt number from Shah and London have constant straight line graph while the current study have an average Nusselt number with high value at the entrance and eventually approaches the fully developed value with good agreement with Shah and London result as the length increase. The discrepancies was that Shah and London applied fully developed flow before the working fluid enter the inlet whereas current studies use uniform inlet velocity which take a while to become fully developed because of the development of thermal entry region at the channel and the values of Nusselt number tend to stabilize after fully develop region has been achieved.

\subsection{Velocity contour}

The velocity contour is an important indicator to showing the behavior of the working fluids in the microchannel, velocity contour at the channel outlet and inlet are presented in Figure 5.

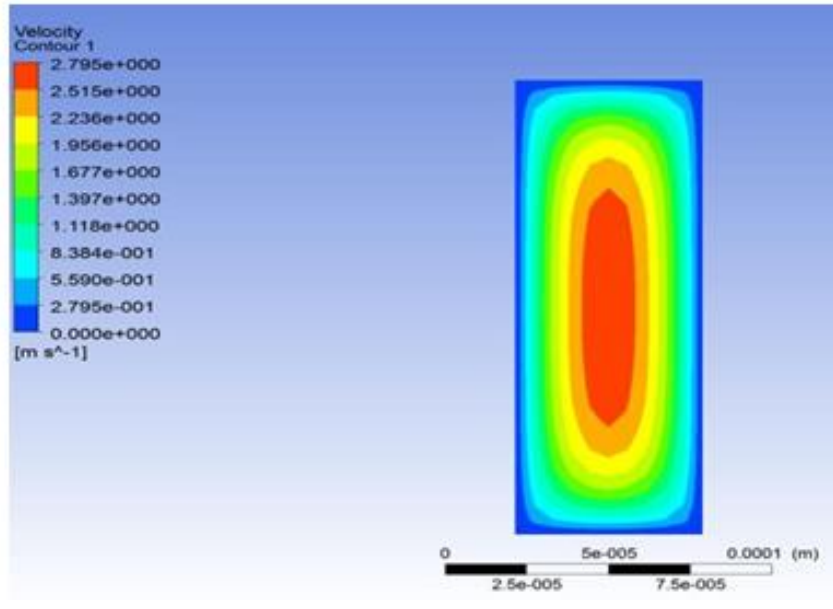

(a) pure water
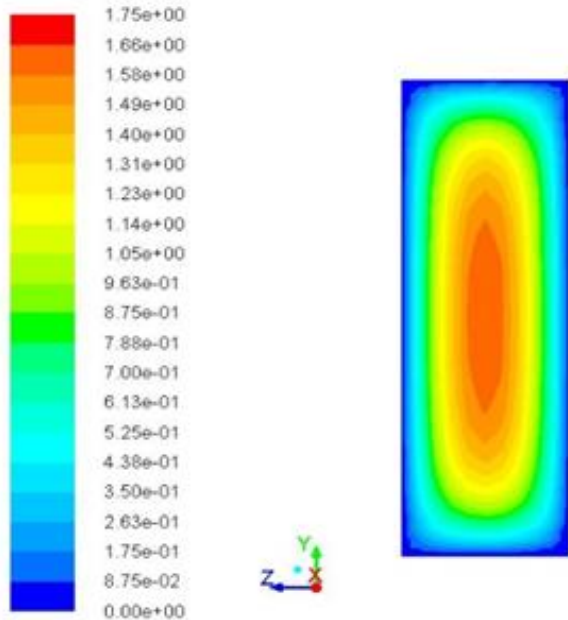

(b) $\mathrm{Fe}_{3} \mathrm{O}_{4}-\mathrm{H}_{2} \mathrm{O}$

Fig. 5. Velocity contour at channel outlet (a) pure water, (b) $\mathrm{Fe}_{3} \mathrm{O}_{4}-\mathrm{H}_{2} \mathrm{O}$

As can be seen from Figure 5(a) and (b), velocity contour at the channel outlet exhibits the highest value at the middle of the channel and approaches zero near the channel wall. The 
phenomenon behind this is that, in the middle of the channel the flow is free from viscous effect while near the wall the flow dominated by viscous effect. Figure 6 shows the velocity contour at the channel inlet, with assumption that the velocity is uniform at the channel inlet which depends on the Reynolds number, it can be seen that the flow is not yet develop at the channel inlet, it take a while to become fully developed. For an internal flow existence of entrance and fully developed region must be consider.
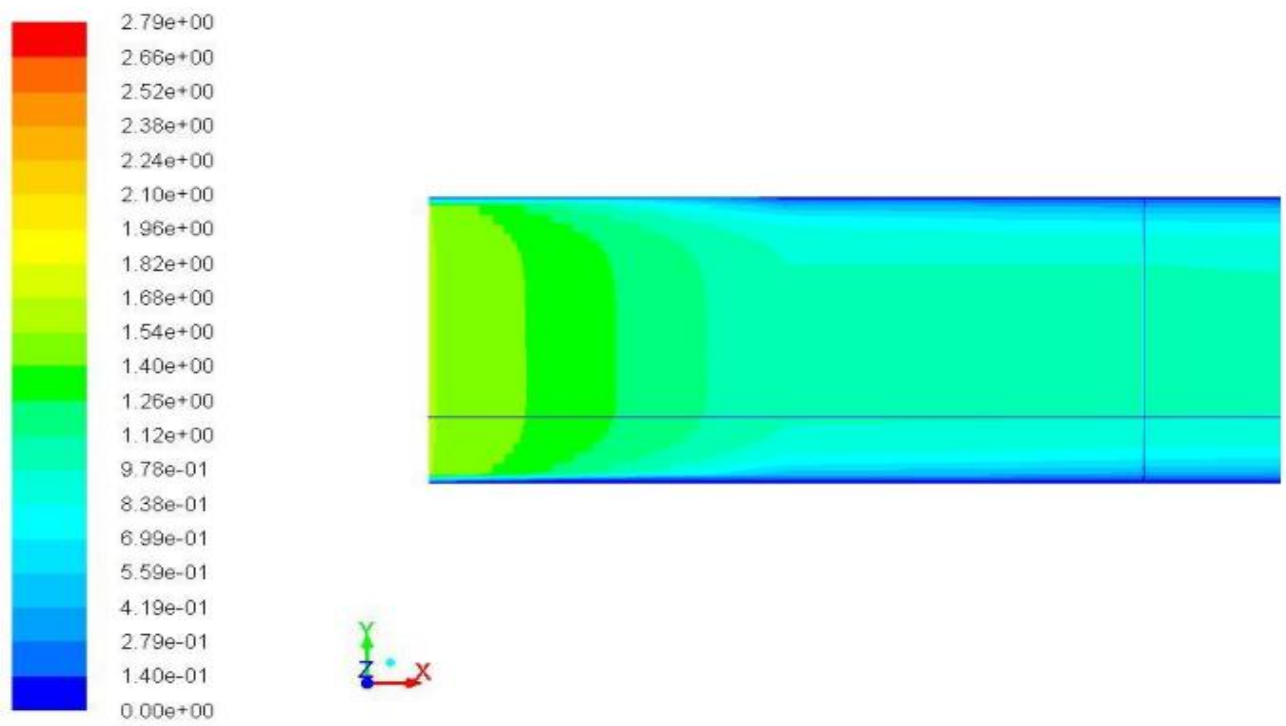

Fig. 6. Closed up view of the velocity contour at the channel inlet

\subsection{Effect of Temperature Distribution}

The temperature contours from the simulation results of pure water and $\mathrm{Fe}_{3} \mathrm{O}_{4}-\mathrm{H}_{2} \mathrm{O}$ as working fluids were taking as plotted in Figure 7 . Fluid nearer to the wall will have high temperature compared to the fluid flow at the core of the channel.

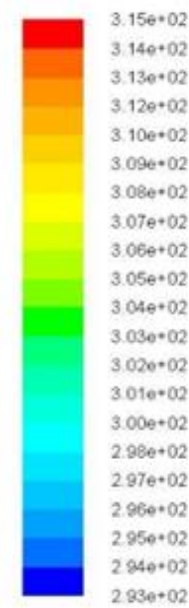

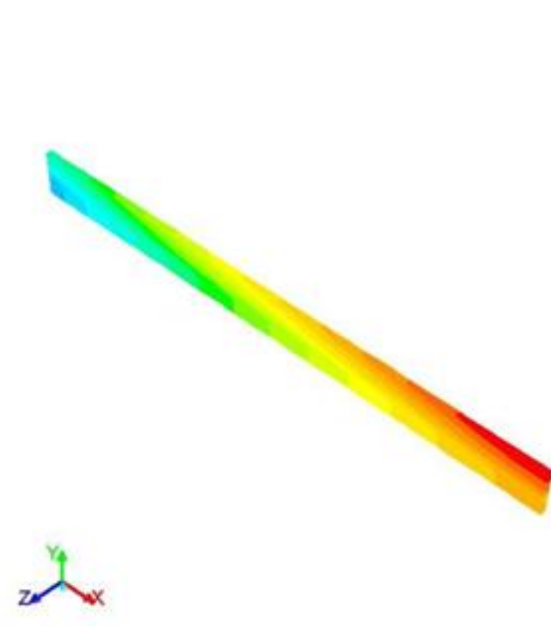

(a) pure water
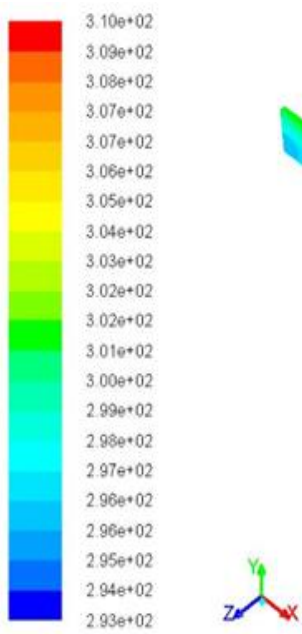

(b) $\mathrm{Fe}_{3} \mathrm{O}_{4}-\mathrm{H}_{2} \mathrm{O}$

Fig. 7. Temperature contour at microchannel (a) pure water, (b) $\mathrm{Fe}_{3} \mathrm{O}_{4}-\mathrm{H}_{2} \mathrm{O}$ as working fluid

These Phenomena shows that the extraction of heat by the working fluid from the solid region is highest near the channel wall compare to the middle part of the channel. It is interesting to note that 
the presence of nano particles has effect of reducing the tempreture of the surfaces as particle volume fraction of $\mathrm{Fe}_{3} \mathrm{O}_{4}-\mathrm{H}_{2} \mathrm{O}$ increases due to its higher dynamic viscosity and lower heat capacity compared to pure water.

\subsection{Effect of Nusselt Number}

Heat transfer performance in microchannel heat sink is analyzed based on Nusselt number. Nusselt number is defined as dimensionless parameter that provides a comparison rate for how fast heat is transferred between materials where convection is taking place, as compared to basic heat transfer by conduction where little internal movement of matter is occurring. Figures 8 to 10 show the graphs of Nusselt number vs length $\mathrm{X}$, taken at the base channel wall of MCHS for pure water and $\mathrm{Fe}_{3} \mathrm{O}_{4}-\mathrm{H}_{2} \mathrm{O}$. The selected Reynolds number are 140, 700 and 1400 and for volume fractions are $\varphi=0.4$, $\varphi=0.6$ and $\varphi=0.8$. From the plots variation of Nusselt number values are observed along the length of microchannel in $\mathrm{x}$ direction.

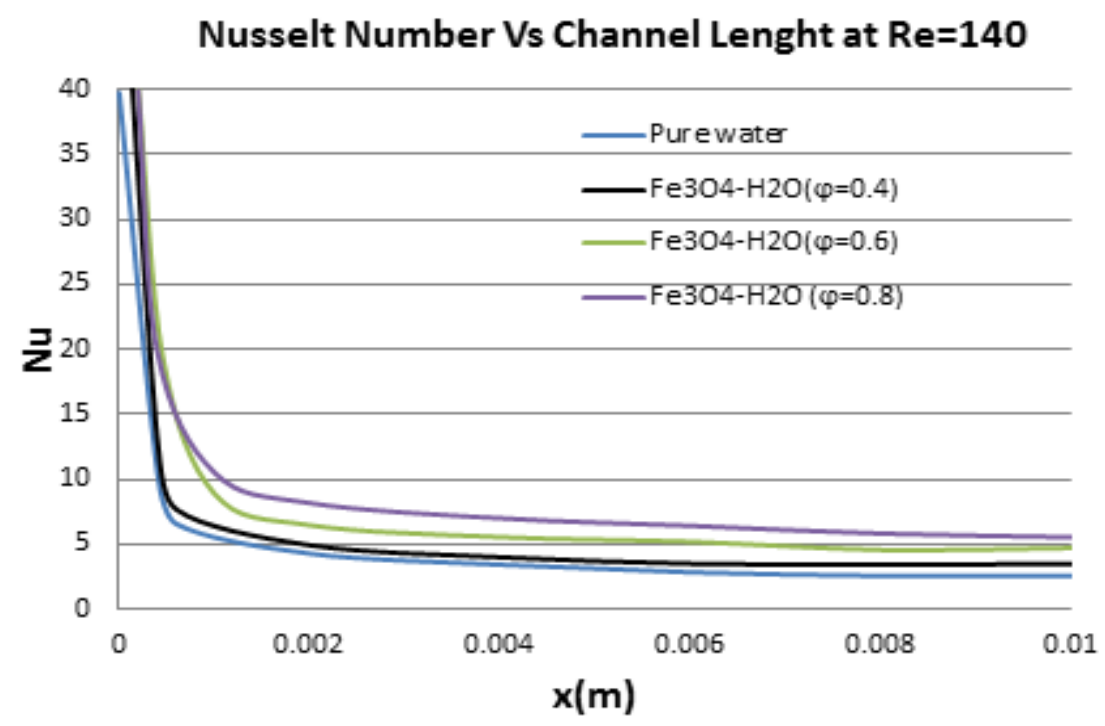

Fig. 8. Nusselt Number (Nu) Vs Channel Length( $\mathrm{x}$ ) at $\mathrm{Re}=140$

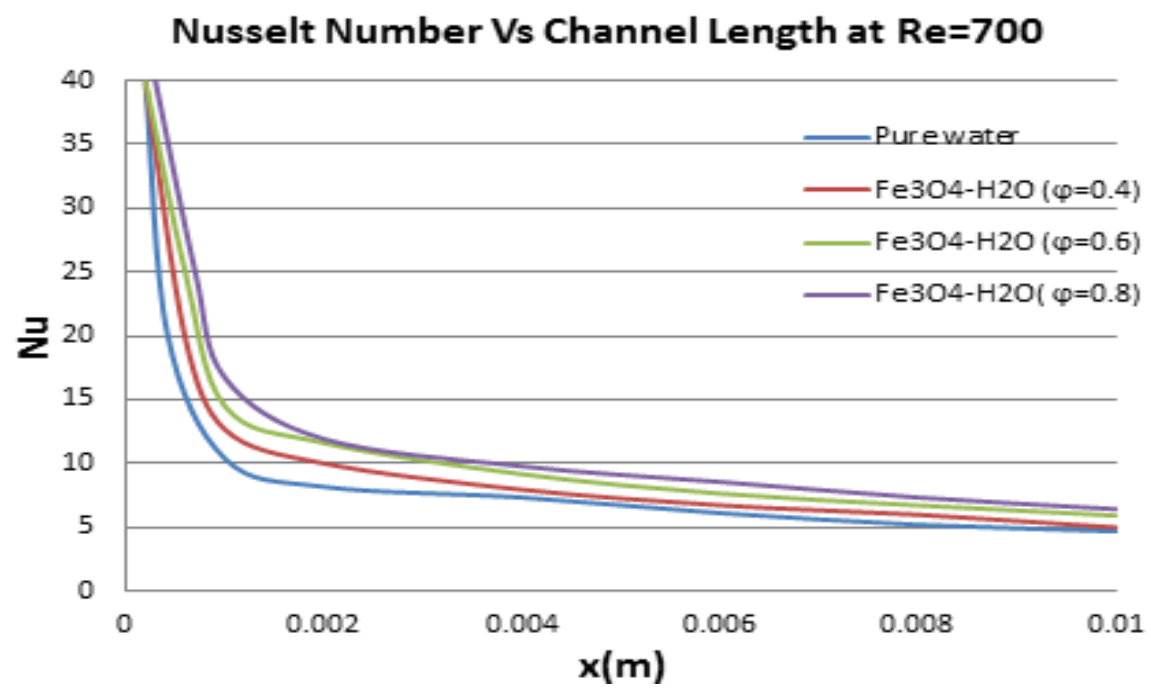

Fig. 9. Nusselt Number (Nu) Vs Channel Length(x) at $\mathrm{Re}=700$ 
Higher Nusselt number is found as fluid enters the channel inlet. This could be anticipated as the result of the development of thermal entry region at the channel and the values of Nusselt number tend to stabilize after fully develop region has been achieved. The energy equation for the entry length is complicated which is why the simple solution to explain the thermal entry length problem is based on assuming that thermal condition develop in the presence of fully develop profile. It would never be the case that thermal conditions are fully developed while the hydrodynamic condition is still developing. It can be seen that as Reynolds number increase, the value of Nusselt number also increase. At the channel outlet the same trend is found, indicating that the length of the thermal develop region is larger than the channel length. For relatively high Reynolds number which is in this case is 1400 , fully developed flow may not be achieved inside the heat sink even there is very small gradient of the average Nusselt number near the channel outlet.

Nusselt Number Vs Channel Lenght at $\mathrm{Re}=1400$

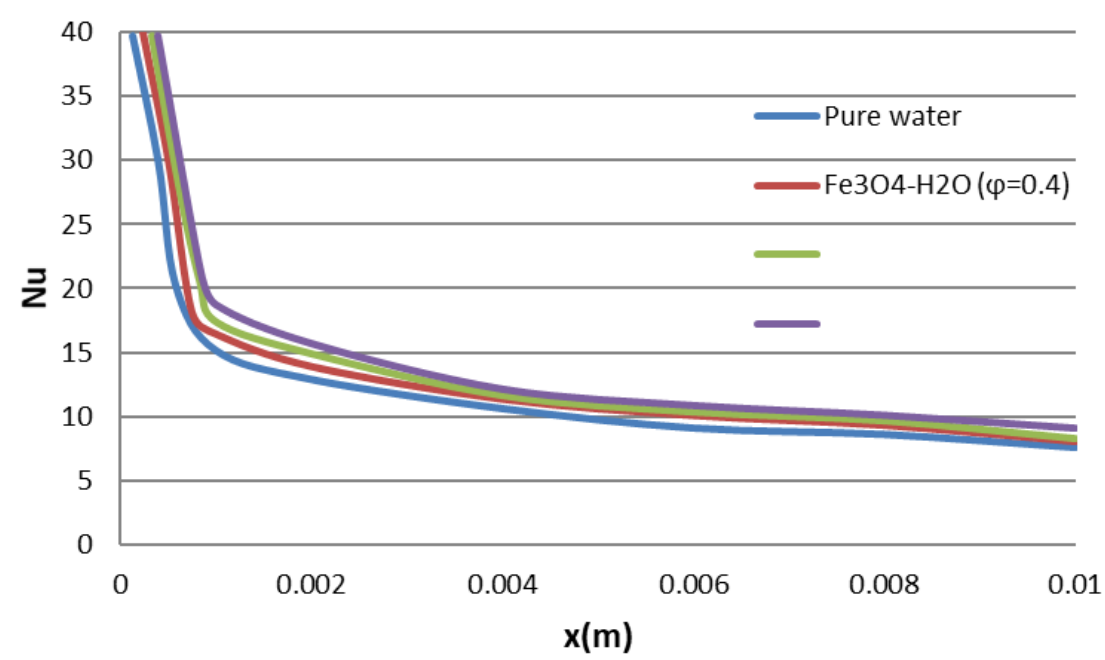

Fig. 10. Nusselt Number (Nu) Vs Channel Length(x) at $\mathrm{Re}=1400$

Figure 11 shows that average Nusselt number increase as Reynolds number increase. This is because the Reynolds number is the function of the velocity. By increasing the Reynolds number, the velocity will increase and the movement of termolecular of fluid will also increase. The interruption of the particle of fluid will increase thus increase the heat being transfer. However, the $0.8 \%$ volume fraction provides the maximum increase in Nusselt number compared to $0.6 \%$ and $0.4 \%$.

Average Nu Vs Re of Pure water and Fe3O4-H2O

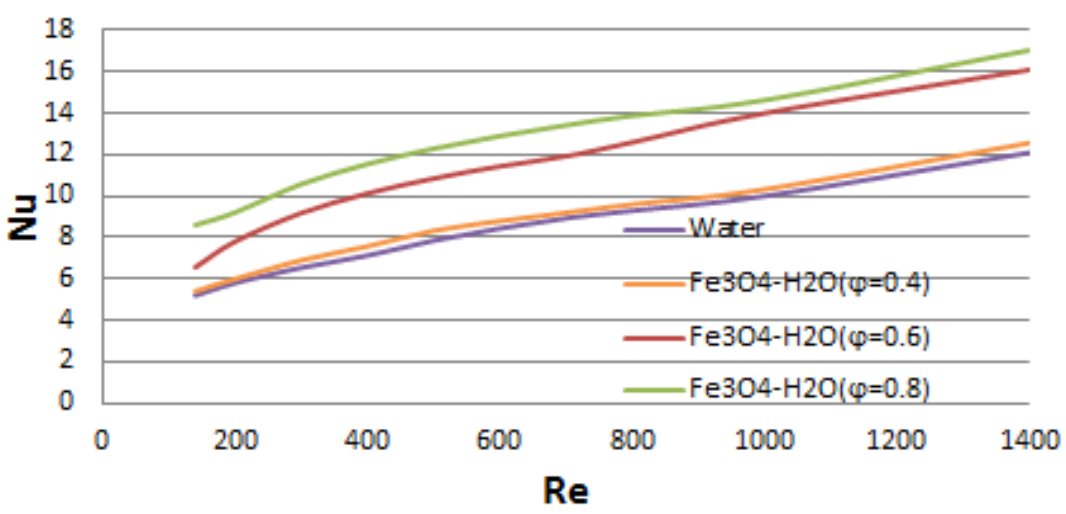

Fig. 10. Average Nusselt Number (Nu) Vs Reynolds Number(Re) 


\section{Conclusions}

In this study, the three-dimensional rectangular silicon microchannel heat sink were analyzed numerically for combine conduction and convection heat transfer to investigate the fluid flow and heat transfer performance using pure water and $\mathrm{Fe}_{3} \mathrm{O}_{4}-\mathrm{H}_{2} \mathrm{O}$ as working fluids, the numerical analysis is done using FLUENT. The simulation employed by applying uniform inlet velocity with constant heat flux applied at the top of the microchannel heat sink. The microchannel heat sink performance is assessed in term of velocity profile, temperature profile and Nusselt number.

It is equally important to note that, as uniform inlet velocity is applied at the channel inlet, it takes an interval of time for the flow to be fully developed flow inside the microchannel the phenomena behind this is because of the developing boundary layer at the channel inlet. Maximum temperature occurred at the heat sink top wall where the constant heat flux is applied.

However, $\mathrm{Fe}_{3} \mathrm{O}_{4}-\mathrm{H}_{2} \mathrm{O}$ with volume fraction $0.8 \%$ provides the maximum temperature reduction of $0.4 \%$ compare to using pure water as working fluid. Increasing the thermal conductivity and volume fraction of the nanoparticle reduces the temperature at the heated surface of heat sink especially near the channel outlet. This is because, $\mathrm{Fe}_{3} \mathrm{O}_{4}-\mathrm{H}_{2} \mathrm{O}$ has higher dynamic viscosity and lower heat capacity compared to pure water.

Nusselt number has been used to determine the heat transfer performance for microchannel heat sink. The results of present work show that the highest heat transfer enhancement is anticipated for $\mathrm{Fe}_{3} \mathrm{O}_{4}-\mathrm{H}_{2} \mathrm{O}$ with volume fraction of $0.8 \%$ which have higher thermal conductivity and have the higher Nusselt number. Absolutely, the simulated results showed that the heat transfer performance of $\mathrm{Fe}_{3} \mathrm{O}_{4}-\mathrm{H} 2 \mathrm{O}$ with $0.8 \%$ was better than that of $\mathrm{Fe}_{3} \mathrm{O}_{4}-\mathrm{H} 2 \mathrm{O}$ with $0.4 \%$, of $\mathrm{Fe}_{3} \mathrm{O}_{4}-\mathrm{H} 2 \mathrm{O}$ with $0.6 \%$, and pure water. Increasing the thermal conductivity of working fluid enhanced the heat transfer performance of microchannel heat sink. $\mathrm{Fe}_{3} \mathrm{O}_{4}-\mathrm{H} 20$ is recommended to achieve overall heat transfer enhancement.

\section{Acknowledgement}

Authors would like to acknowledge Takasago Thermal Engineering Ltd and Universiti Teknologi Malaysia (Grant no. 4B314) for supporting this research activity.

\section{References}

[1] Bar-Cohen, Yoseph, Sean P. Leary, Mohsen Shahinpoor, Joycelyn S. Harrison, and Joseph G. Smith. "Electroactive polymer (EAP) actuators for planetary applications." In Smart Structures and Materials 1999: Electroactive Polymer Actuators and Devices, vol. 3669, pp. 57-63. International Society for Optics and Photonics, 1999.

https://doi.org/10.1117/12.349708

[2] M.F. Ben Achour, A. Bar-Cohen, Heat sink optimization for maximum performance and minimum mass, ASME EEP 26 (1999) 737-747.

[3] Tuckerman, Davic B. Heat-transfer microstructures for integrated circuits. No. UCRL-53515. Lawrence Livermore National Lab CA, 1984.

[4] Parida, Pritish Ranjan. "Experimental investigation of heat transfer rate in micro-channels." Master Thesis. (2007).

[5] Mudawar, Issam. "Assessment of high-heat-flux thermal management schemes." IEEE transactions on components and packaging technologies 24, no. 2 (2001): 122-141.

https://doi.org/10.1109/6144.926375

[6] Gunnasegaran, P., N. H. Shuaib, H. A. Mohammed, MF Abdul Jalal, and E. Sandhita. "Heat transfer enhancement in microchannel heat sink using nanofluids." Fluid Dynamics, Computational Modeling and Applications (2012): 287326.

https://doi.org/10.5772/26903

[7] Peng, X. F., and G. P. Peterson. "The effect of thermofluid and geometrical parameters on convection of liquids through rectangular microchannels." International Journal of Heat and Mass Transfer 38, no. 4 (1995): 755-758. https://doi.org/10.1016/0017-9310(95)93010-F 
[8] Qu, Weilin, and Issam Mudawar. "Analysis of three-dimensional heat transfer in micro-channel heat sinks." International Journal of heat and mass transfer 45, no. 19 (2002): 3973-3985.

https://doi.org/10.1016/S0017-9310(02)00101-1

[9] Murugesan, Chandrasekar, and Suresh Sivan. "Limits for thermal conductivity of nanofluids." Thermal science 14, no. 1 (2010): 65-71.

https://doi.org/10.2298/TSCI1001065M

[10] Xie, Huaqing, Jinchang Wang, Tonggeng Xi, Yan Liu, Fei Ai, and Qingren Wu. "Thermal conductivity enhancement of suspensions containing nanosized alumina particles." Journal of applied physics 91, no. 7 (2002): 4568-4572. https://doi.org/10.1063/1.1454184

[11] Xuan, Yimin, and Qiang Li. "Investigation on convective heat transfer and flow features of nanofluids." J. Heat transfer 125, no. 1 (2003): 151-155. https://doi.org/10.1115/1.1532008

[12] Lee, S., SU-S. Choi, S, and Li, and J. A. Eastman. "Measuring thermal conductivity of fluids containing oxide nanoparticles." (1999): 280-289.

https://doi.org/10.1115/1.2825978

[13] Sundar, L. Syam, Manoj K. Singh, and Antonio CM Sousa. "Investigation of thermal conductivity and viscosity of Fe304 nanofluid for heat transfer applications." International communications in heat and mass transfer 44 (2013): 7-14.

https://doi.org/10.1016/j.icheatmasstransfer.2013.02.014

[14] Abdolbaqi Mohammed Kdhder, Nor Azwadi Che Sidik, Siti Nurul Akmal Yusof. "Heat Transfer Enhancement in Straight Channel with Nanofluid in Fully Developed Turbuleny Flow" Journal of Advanced Research in Applied Mechanics 63, no. 1 (2019): 1-15.

[15] Wang, Xiang-Qi, and Arun S. Mujumdar. "Heat transfer characteristics of nanofluids: a review." International journal of thermal sciences 46, no. 1 (2007): 1-19.

https://doi.org/10.1016/i.ijthermalsci.2006.06.010

[16] Das, Sarit Kumar, Nandy Putra, Peter Thiesen, and Wilfried Roetzel. "Temperature dependence of thermal conductivity enhancement for nanofluids." J. Heat Transfer 125, no. 4 (2003): 567-574. https://doi.org/10.1115/1.1571080

[17] Wang, Xinwei, Xianfan Xu, and Stephen US Choi. "Thermal conductivity of nanoparticle-fluid mixture." Journal of thermophysics and heat transfer 13, no. 4 (1999): 474-480.

https://doi.org/10.2514/2.6486

[18] Chein, Reiyu, and Jason Chuang. "Experimental microchannel heat sink performance studies using nanofluids." International journal of thermal sciences 46, no. 1 (2007): 57-66. https://doi.org/10.1016/j.ijthermalsci.2006.03.009

[19] Lee, Jaeseon, and Issam Mudawar. "Assessment of the effectiveness of nanofluids for single-phase and two-phase heat transfer in micro-channels." International Journal of Heat and Mass Transfer 50, no. 3-4 (2007): 452-463. https://doi.org/10.1016/j.ijheatmasstransfer.2006.08.001

[20] Mohammed, H. A., Prem Gunnasegaran, and N. H. Shuaib. "The impact of various nanofluid types on triangular microchannels heat sink cooling performance." International Communications in Heat and Mass Transfer 38, no. 6 (2011): 767-773. https://doi.org/10.1016/i.icheatmasstransfer.2011.03.024

[21] Fani, B., A. Abbassi, and M. Kalteh, Effect of nanoparticles size on thermal performance of nanofluid in a trapezoidal microchannel-heat-sink. International Communications in Heat and Mass Transfer, 2013. 45: p. 155-161. https://doi.org/10.1016/j.icheatmasstransfer.2013.04.003

[22] Tsai, T.-H. and R. Chein, Performance analysis of nanofluid-cooled microchannel heat sinks. International Journal of Heat and Fluid Flow, 2007. 28(5): p. 1013-1026. https://doi.org/10.1016/j.ijheatfluidflow.2007.01.007

[23] Bhattacharya, P., A. N. Samanta, and S. Chakraborty. "Numerical study of conjugate heat transfer in rectangular microchannel heat sink with Al 2 O 3/H 2 O nanofluid." Heat and Mass Transfer 45, no. 10 (2009): 1323-1333. https://doi.org/10.1007/s00231-009-0510-0

[24] Mohamad Noh, N. H., Fazeli, A., and Che Sidik, N. A. "Numerical Simulation of Nanofluids for Cooling Efficiency in Microchannel Heat Sink." Journal of Advanced Research in Fluid Mechanics and Thermal Sciences 4, no. 1 (2014): 13-23. 